Note

\title{
Vasorelaxation by L-Arginine after L-NAME Administration in Rabbits Consuming Moderate Amounts of Red Wine
}

\author{
Yasuhisa WAKABAYASH ${ }^{*}$ \\ Department of Medicine, University of Kitasato Medical School, \\ 1-15-1 Kitasato, Sagamihara 228-8555, Japan
}

(Received November 15, 2001)

\begin{abstract}
Summary Red wine and its constituents have been shown to stimulate endothelium-dependent and nitric oxide (NO)-mediated vasorelaxation in vitro in the isolated and precontracted aortic rings. The present study investigated if this occurred in vivo in rabbits, which chronically consumed a moderate amount of red wine. $\mathrm{N}^{\omega}$ nitro-L-arginine-methyl ester (LNAME) and L-arginine was infused into the rabbits that consumed red wine $(7 \mathrm{~mL} / \mathrm{kg} / \mathrm{d})$, ethanol $(99.5 \%, 0.8 \mathrm{~mL} / \mathrm{kg} / \mathrm{d})$, or water alone for 4 weeks, and the vaso-constrictive/-dilative response was studied in the renal artery. Following treatment with L-NAME ( $30 \mathrm{mg} / \mathrm{kg}$ ), the renal blood flow rate decreased and renal vascular resistance increased. Only in the animals consuming red wine did a subsequent administration of L-arginine $(300 \mathrm{mg} / \mathrm{kg})$ increase the renal blood flow rate and decrease the renal vascular resistance. The effects were associated with the increase in the renal $\mathrm{NO}$ metabolite (nitrite/nitrate, $\mathrm{NO}_{2}{ }^{-} / \mathrm{NO}_{3}{ }^{-}$) production rate. From the present in vivo model, it is suggested that vasorelaxation by L-arginine is through the NO pathway and that the effects observed in the animals consuming the red wine cannot be attributed to alcohol alone.
\end{abstract}

Key Words red wine, ethanol, nitric oxide, nitrite/nitrate

Factors playing a part in the acute occlusion of the coronary artery are atherosclerotic lesion progression (1), instability of plaques (2), increased thrombogenicity (3), and dysfunction of endothelium (4). Since a moderate consumption of red wine has been shown to reduce the incidence of the acute coronary syndrome $(5,6)$, it is possible that this consumption modulates these factors. In their in vivo studies, Klurfeld and Kritchevsky (7) and Wakabayashi (8) investigated the effect of red wine on coronary atherosclerotic lesion progression in rabbits, meeting with controversial results. Wollny et al. (9) studied its effect on the thrombogenicity in rats in vivo and showed that a consumption of red wine prevented experimental thrombosis through the nitric oxide (NO) pathway. The possibility that red wine might modulate another factor, endothelial dysfunction, is suggested from several in vitro studies, in which red wine or its constituents was shown to induce vasorelaxation in the isolated and precontracted aortic rings. The mechanism is also through an NO pathway $(10-14)$. It is not fully established how red wine would modulate vascular tone through the NO pathway. One possibility would be that red wine activates nitric oxide synthase (NOS). The present study was undertaken to study if NO-mediated vasorelaxation occurs in vivo in rabbits that consume moderate amounts of red wine

* Present address: Department of Medicine, Kitasato Institute Hospital, 5-9-1 Shirokane, Minato, Tokyo 108-8642, Japan

E-mail: wakabayashi-y@kitasato.or.jp chronically. The response of renal blood flow rate to Larginine (the substrate of $\mathrm{NO}$ ) was investigated in the rabbits pretreated with NOS inhibitor $\left(\mathrm{N}^{\omega}\right.$ nitro-L-arginine-methyl ester, L-NAME). The response was then assessed with reference to the renal products of NO metabolites, nitrite/nitrate $\left(\mathrm{NO}_{2}{ }^{-} / \mathrm{NO}_{3}{ }^{-}\right)$.

\section{Materials and Methods}

Animals, wine, and ethanol. All procedures and protocols were approved by the Animal Experiment Ethics Committee of Kitasato University and carried out in line with the Kitasato University guide for the care and use of laboratory animals, which was in compliance with the NIH Guide for the Care and Use of Laboratory Animals, NIH Publication N. 85-23, 1985. Male New Zealand white rabbits 8 weeks old were housed individually in metal cages in a room controlled at $22^{\circ} \mathrm{C}$ and $40-45 \%$ humidity on a $14 \mathrm{~h}$-light/10 h-dark cycle. They were fed a standard rabbit diet (CR1, $120 \mathrm{~g}$ daily, CLEA Japan, Tokyo) and allowed free access to a water nozzle that was equipped individually in each cage. A week later, alcoholic beverages were added. Seven rabbits, weighing $1.8 \pm 0.1 \mathrm{~kg}$, mean \pm standard error of the mean (SE), were provided with red wine. Seven rabbits, $2.0 \pm 0.1 \mathrm{~kg}$, were provided with ethanol. Six rabbits, $1.9 \pm 0.1 \mathrm{~kg}$, had water only. The red wine used was Japanese pinot noir (Fujimien 1993, Suntory Tomi no oka Winery, Japan) generously provided by Suntory Ltd. Its total polyphenol content was $2,770 \mathrm{mg} / \mathrm{L}$, and its alcohol content was $11.8 \%$ by volume. A dose of $7 \mathrm{~mL} / \mathrm{kg}$ (body weight) of red wine was mixed with water. The 
solution $(50 \mathrm{~mL}$ in total) was put in a plastic bottle, which was hung in front of individual cages, to allow spontaneous drinking. For animals consuming ethanol, $0.8 \mathrm{~mL} / \mathrm{kg}$ (body weight) of synthetic ethanol (99.5\%) was given in the same manner as red wine. Both red wine and ethanol were freshly prepared every morning. The dose was adjusted according to the change in body weight that was measured once a week. Beverages were given for $4 \mathrm{wk}$ before the animals were subject to in vivo hemodynamic studies. The rabbits consumed all alcoholic beverages each day.

Hemodynamic studies. The rabbits were anesthetized with sodium pentobarbital $(25 \mathrm{mg} / \mathrm{kg}$ given intravenously). A lactated Ringer solution was infused through the ear vein at a rate of $20 \mathrm{~mL} / \mathrm{kg} / \mathrm{h}$ to compensate for the loss of body fluid during surgery. Tracheostomy was performed, and the animals were put on a respirator. Following laparotomy, the right renal artery was ligated and an electromagnetic flow probe with a lumen diameter of $1.5 \mathrm{~mm}$ (model FJ D1 5 T, Nihon Koden, Tokyo, Japan) was positioned around the left renal artery. The renal blood flow rate was measured continuously with an internally calibrated flow meter (model MFV 3100, Nihon Koden). A Teflon catheter was placed in the right femoral artery for the continuous measurement of arterial blood pressure with a model 363 polygraph, NEC Sanei, Tokyo, Japan. Another Teflon catheter was inserted in the left femoral artery. Its tip was advanced to the abdominal aorta and placed just above the left renal artery. This line was used for the infusion of drugs. Finally, a polyurethane catheter was placed in the right renal vein. This line was used to collect renal venous blood for the measurement of $\mathrm{NO}_{2}{ }^{-} / \mathrm{NO}_{3}{ }^{-}$concentration. After the completion of preparations, an equilibration period of half an hour was allowed, and the hemodynamic responses to L-NAME $(30 \mathrm{mg} / \mathrm{kg})$ and L-arginine $(300 \mathrm{mg} / \mathrm{kg})$ were studied. The doses were determined from the preliminary dose-response studies if an increase or decrease of renal blood flow rate of more than $10 \%$ was achieved. The drugs were dissolved with normal saline, and LNAME was infused intra-arterially for 5 min (at the rate of $1 \mathrm{~mL} / \mathrm{min}$ ); after a 5 -min interval, L-arginine was infused for $5 \mathrm{~min}$ (at the rate of $1 \mathrm{~mL} / \mathrm{min}$ ). Before and after the infusion of each drug, the arterial blood pressure and the renal blood flow rate were analyzed by averaging values during a 15 -s period with a computer using a PowerLab program. Renal vascular resistance was then obtained by dividing arterial blood pressure by the renal blood flow rate. The renal venous blood was collected at the same time. After the final measurement was completed, the rabbits were killed by an overdose of sodium pentobarbital.

Assays. Total polyphenol content was measured by use of the Folin-Ciocalteau method (15). The blood ethyl alcohol content on the day of the study was determined by gas chromatography. The serum $\mathrm{NO}_{2}{ }^{-} / \mathrm{NO}_{3}{ }^{-}$ was determined with an autoanalyzer on the basis of the Griess reaction, as previously reported (16). The renal $\mathrm{NO}_{2}{ }^{-} / \mathrm{NO}_{3}{ }^{-}$production rate was calculated by multiplying renal blood flow rate and renal venous $\mathrm{NO}_{2}{ }^{-} / \mathrm{NO}_{3}{ }^{-}$concentration.

Statistics. Data were expressed as means \pm SE. The overall differences among the groups was evaluated by a repeated measure of ANOVA, using an SAS package. A post hoc test (Fisher's least significant difference, LSD) was performed when there was a significant difference as a result of ANOVA $(p<0.05)$.

\section{Results}

The mean body weights on the day of the hemodynamic studies were $2.4 \pm 0.1 \mathrm{~kg}$ (water alone), $2.4 \pm 0.1$ $\mathrm{kg}$ (red wine), and $2.6 \pm 0.1 \mathrm{~kg}$ (ethanol). The blood ethanol content was less than the limit of detection $(0.07 \mathrm{mmol} / \mathrm{L})$ in all the animals. Before L-NAME infusion, the renal blood flow rate was not significantly different among the animals consuming water only, water and red wine, or water and ethanol. The administration of L-NAME resulted in a decrease in renal blood flow rate and an increase in renal vascular resistance in all groups. The subsequent administration of L-arginine resulted in an increase in renal blood flow rate and a decrease in renal vascular resistance only in the animals consuming red wine. The renal blood flow rate remained decreased and renal vascular resistance remained increased in the animals consuming water only or ethanol (Fig. 1A, B). However, the significant difference in the renal blood flow rate and the renal vascular resistance was noted only between the rabbits consuming only water and red wine after the administration of L-arginine. The renal $\mathrm{NO}_{2}{ }^{-} / \mathrm{NO}_{3}{ }^{-}$production rate showed a trend comparable to the renal blood flow rate (Fig. 1C). The analysis among the three groups of animals again showed a significant difference between animals consuming red wine and water alone only after the administration of L-NAME and L-arginine.

\section{Discussion}

Following the treatment with L-NAME, the administration of L-arginine increased the renal blood flow rate and decreased the renal vascular resistance only in the animals consuming red wine. This finding suggested that nitric oxide synthase had not been equally inactivated by L-NAME among the rabbits consuming different beverages. Since the vasodilative effect by L-arginine was associated with the increase in the renal $\mathrm{NO}_{2}{ }^{-}$/ $\mathrm{NO}_{3}{ }^{-}$production rate, it could be possible that the chronic consumption of red wine might have modulated the NO system by activating NOS. However, this possibility remains to be determined, since the direct measurement of NOS protein or the increase in its mRNA expression was not performed in the present study. As the effect by L-arginine was not observed in the animals consuming ethanol, the effect displayed by the red wine-consuming animals cannot be attributed to alcohol alone. The red wine used in the present study contained a sizable amount of polyphenol. Karim et al. (14) demonstrated that polymeric polyphenol from cocoa activated the endothelial NOS in vitro. Therefore polyphenol may have participated in the vasodilatory 

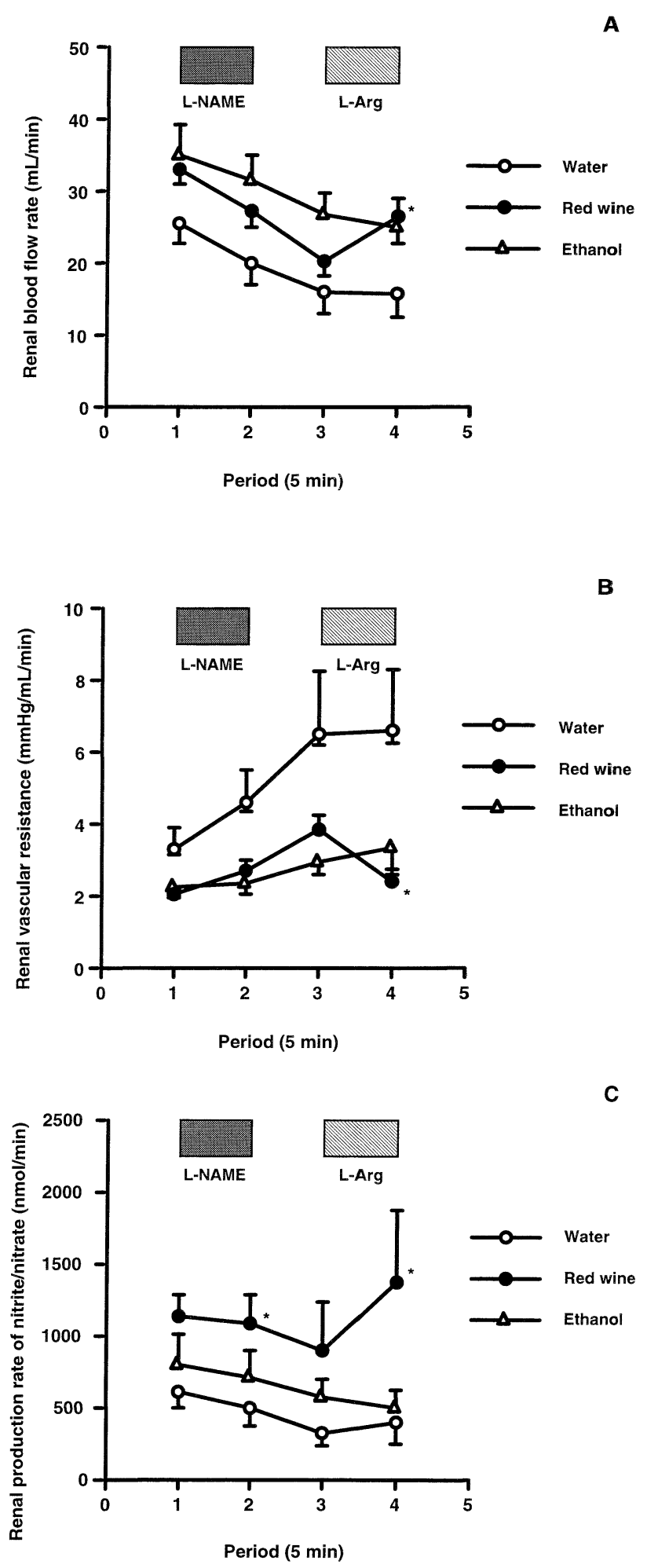

Fig. 1. Effect of L-NAME and L-arginine (L-Arg) on the renal blood flow rate (A), renal vascular resistance $(B)$, and renal nitrite/nitrate production rate $(C)$ in rabbits consuming water $(n=6)$, red wine $(n=7)$, and ethanol $(n=7)$. The points are mean and error bars are \pm 1 SE. Each period consists of 5 min. ${ }^{*} p<0.05$ for red wine compared to water by Fisher's LSD test. response in the present model, but the participation of constituents other than polyphenol and alcohol cannot be excluded.

The treatment of L-NAME could analogize with certain pathological conditions such as atherosclerosis. The decrease in NO production and endothelial dysfunction was reported in the early stage of atherosclerosis $(17,18)$. The oxidized low-density lipoprotein, which plays crucial roles in the development of atherosclerosis (19), has been shown to decrease the expression of endothelial NOS (20). Furthermore, chronic red wine consumption was shown to prevent low-density lipoprotein from being oxidized in the atherosclerosis models $(8)$. So if red wine had the activity to activate endothelial NOS in addition to the antioxidant action, its consumption could be beneficial for atherosclerosis.

Although the vasodilatory effect was attributed not only to alcohol in the present model, the values of the renal blood flow rate or the renal vascular resistance themselves were not significantly different from those in the animals consuming red wine. This finding would raise the possibility that ethanol might have a vasorelaxation activity independent of the NO pathway. Therefore it cannot be excluded that ethanol and other nonalcoholic components of red wine act synergistically toward this vasorelaxatory effect.

From the present in vivo model, it is suggested that a chronic consumption of red wine modulates renal vascular tone in rabbits via NOS, possibly by activating nitric oxide synthase. The effects observed in this system cannot be attributed to alcohol alone.

\section{Acknowledgments}

The author would like to thank Mr. Shigeyoshi Maruyama for his excellent technical assistance and Mr. Alan A. Brownlee, University of Cambridge, and Dr. Rosemary L. Walzem, Texas A\&M University, for comments on the manuscript. This work was supported in part by a university grant, 89034-3564.

\section{REFERENCES}

1) Brown BG, Zhao X-Q, Sacco DE, Albers JJ. 1993. Lipid lowering and plaque regression. New insights into prevention of plaque disruption and clinical events in coronary disease. Circulation 87: 1781-1791.

2) Brown G, Albers JJ, Fisher LD, Shaeffer SM, Lin JT, Kaplan C, Zhao X-Q, Bisson BD, Fitzpatrick V, Dodge HT. 1990. Regression of coronary artery disease as a result of intensive lipid-lowering therapy in men with high levels of apolipoprotein B. N Engl J Med 323: 1289 1298.

3) Lacoste L, Lam JYT, Hung J, Letchacovski G, Solymoss CB, Waters D. 1995. Hyperlipidemia and coronary disease. Correction of the increased thrombogenic potential with cholesterol reduction. Circulation 92: 31723177.

4) Leung W-H, Lau C-P, Wong C-K. 1993. Beneficial effect of cholesterol-lowering therapy on coronary endothelium-dependent relaxation in hypercholesterolaemic patients. Lancet 341: 1496-1500.

5) St. Legar AS, Cochrane AL, Moore F. 1979. Factors associated with cardiac mortality in developed countries 
with particular reference to the consumption of wine. Lancet 1 (8124): 1017-1020.

6) Renaud S, de Lorgeril M. 1992. Wine, alcohol, platelets, and the French paradox for coronary heart disease. Lancet 339 (8808): 1523-1526.

7) Klurfeld DM, Kritchevsky D. 1981. Differential effects of alcoholic beverages on experimental atherosclerosis in rabbits. Exp Mol Pathol 34: 62-71.

8) Wakabayashi Y. 1999. Effect of red wine consumption on low-density lipoprotein oxidation and atherosclerosis in aorta and coronary artery in Watanabe heritable hyperlipidemic rabbits. J Agric Food Chem 47: 4724 4730.

9) Wollny T, Aielld L, di Tommaso D, Bellavia V, Rotilio D, Donati MB, de Gaetano G, Iacoviello L. 1999. Modulation of haemostatic function and prevention of experimental thrombosis by red wine in rats: a role for increased nitric oxide production. Br J Pharmacol 127: $747-755$.

10) Fitzpatrick DF, Hirshfield SL, Coffey RG. 1993. Endothelium-dependent vasorelaxing activity of wine and other grape products. Am J Physiol 265: H774H778.

11) Andriambeloson E, Kleschyov AL, Muller S, Beretz A, Stoclet JC, Andriantsitohaina R. 1997. Nitric oxide production and endothelium-dependent vasorelaxation induced by wine polyphenols in rat aorta. Br J Pharmacol 120: 1053-1058.

12) Cishek MB, Galloway MT, Karim M, German JB, Kappagoda CT. 1997. Effect of red wine on endothelium-dependent relaxation in rabbits. Clin Sci 93: 507511.
13) Flesch M, Schwarz A, Bohm M. 1998. Effects of red and white wine on endothelium-dependent vasorelaxation of rat aorta and human coronary arteries. Am J Physiol 275: H1183-H1190.

14) Karim M, McCormick K, Kappagoda CT. 2000. Effects of cocoa extracts on endothelium-dependent relaxation. J Nutr 130: 2105S-2108S.

15) Singleton VL, Rossi JA. 1965. Colorimetry of total phenolics with phosphomolybdic-phosphotungstic acid reagents. Am J Enol Vitic 16: 144-158.

16) Wakabayashi Y, Kikawada R. 1996. Effect of L-arginine on myoglobin-induced acute renal failure in the rabbit. Am J Physiol 270: F784-F789.

17) Cayatte AJ, Palacino JJ, Horten K, Cohen RA. 1994. Chronic inhibition of nitric oxide production accelerates neointimal formation and impairs endothelial function in hypercholesterolemic rabbits. Arterioscler Thromb 14: 753-759.

18) Mano T, Matsuyama T, Yamamoto K, Naito J, Kondo H, Nagano R, Tanouchi J, Hori M, Inoue M, Kamada T. 1996. Endothelial dysfunction in the early stage of atherosclerosis precedes appearnce of intimal lesions assessable with intravascular ultrasound. Am Heart J 131: 231-238.

19) Steinberg D, Parathasarathy S, Carew T, Khoo JC, Witztum JL. 1989. Beyond cholesterol: modifications of low-density lipoprotein that increases its atherogenicity. N Engl J Med 320: 915-924.

20) Liao JK, Shin WS, Lee WY, Clark SL. 1995. Oxidized low-density lipoprotein decreases the expression of endothelial nitric oxide synthase. I Biol Chem 270: 319-324. 